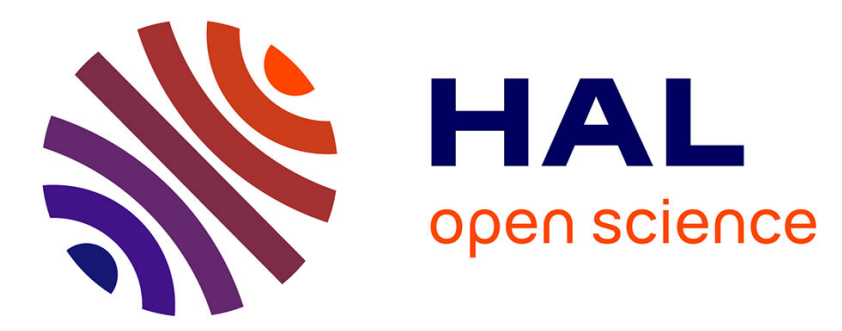

\title{
Moving forward is not only a metaphor: Approach and Avoidance Lead to Self-Evaluative Assimilation and Contrast
}

Marie-Pierre Fayant, Dominique Muller, Cécile Nurra, Theodore Alexopoulos, Richard Palluel-Germain

\section{To cite this version:}

Marie-Pierre Fayant, Dominique Muller, Cécile Nurra, Theodore Alexopoulos, Richard PalluelGermain. Moving forward is not only a metaphor: Approach and Avoidance Lead to Self-Evaluative Assimilation and Contrast. Journal of Experimental Social Psychology, 2010, 47 (1), pp.241. 10.1016/j.jesp.2010.07.013 . hal-00918805

\section{HAL Id: hal-00918805 https://hal.science/hal-00918805}

Submitted on 15 Dec 2013

HAL is a multi-disciplinary open access archive for the deposit and dissemination of scientific research documents, whether they are published or not. The documents may come from teaching and research institutions in France or abroad, or from public or private research centers.
L'archive ouverte pluridisciplinaire HAL, est destinée au dépôt et à la diffusion de documents scientifiques de niveau recherche, publiés ou non, émanant des établissements d'enseignement et de recherche français ou étrangers, des laboratoires publics ou privés. 


\section{Accepted Manuscript}

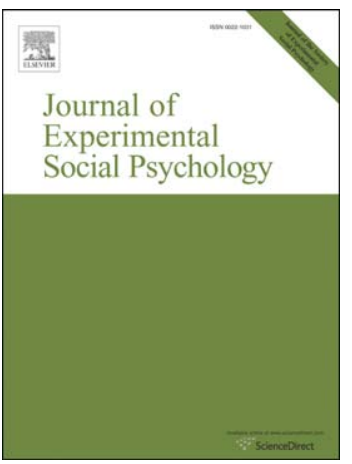

Moving forward is not only a metaphor: Approach and Avoidance Lead to Self-Evaluative Assimilation and Contrast

Marie-Pierre Fayant, Dominique Muller, Cécile Nurra, Theodore Alexopoulos, Richard Palluel-Germain

PII:

S0022-1031(10)00164-2

DOI: doi: 10.1016/j.jesp.2010.07.013

Reference:

YJESP 2506

To appear in: Journal of Experimental Social Psychology

Received date: 26 February 2010

Revised date: $\quad 15$ July 2010

Please cite this article as: Fayant, M.-P., Muller, D., Nurra, C., Alexopoulos, T. \& Palluel-Germain, R., Moving forward is not only a metaphor: Approach and Avoidance Lead to Self-Evaluative Assimilation and Contrast, Journal of Experimental Social Psychology (2010), doi: 10.1016/j.jesp.2010.07.013

This is a PDF file of an unedited manuscript that has been accepted for publication. As a service to our customers we are providing this early version of the manuscript. The manuscript will undergo copyediting, typesetting, and review of the resulting proof before it is published in its final form. Please note that during the production process errors may be discovered which could affect the content, and all legal disclaimers that apply to the journal pertain. 
Moving forward is not only a metaphor: Approach and Avoidance Lead to Self-Evaluative Assimilation and Contrast

Marie-Pierre Fayant

University of Grenoble, France

\section{Dominique Muller}

University of Grenoble and University Institute of France, France

Cécile Nurra

University of Grenoble, France

Theodore Alexopoulos

University Paris Descartes, France

Richard Palluel-Germain

University of Grenoble, France

WORD COUNT: 2,897 


\begin{abstract}
Could it be that walking toward (vs. away) information about someone else changes what you think you are in the direction of what this person is? We answer positively and argue that approach movements lead to self-evaluative assimilation (a higher self-evaluation with a high vs. a low standard), while avoidance movements lead to self-evaluative contrast (a lower selfevaluation with a high vs. a low standard). Hence, we predict that approach and avoidance moderate the impact of comparison information on self-evaluation. To test this idea, participants were either primed with approach or avoidance before processing comparison information (Study 1) or physically had to walk toward or away from this information (Studies 2 and 3). Results on self-evaluated adjustment (Studies 1 and 2) and self-evaluated attractiveness measures (Study 3 ) confirmed our predictions. These studies suggest ways to behave to feel positively about ourselves when hearing about others.
\end{abstract}

Keywords: Approach, Avoidance, Social comparison, Self-evaluation, Assimilation, Contrast 
Moving forward is not only a metaphor: Approach and Avoidance Leads to Self-Evaluative Assimilation and Contrast

When you feel smarter after comparing with Sherlock Holmes than after comparing with Homer Simpson, you are experiencing an assimilation effect. Conversely, when you feel dumber after comparing with Sherlock Holmes than after comparing with Homer Simpson, you are experiencing a contrast effect. Here, we suggest that a critical variable for predicting assimilation and contrast is whether you literally approach or avoid information about these two comparison targets.

The social comparison literature showed that assimilation and contrast depend on several factors (Stapel \& Suls, 2007). For instance, thinking we are similar versus dissimilar with the comparison target leads respectively to assimilation and contrast (Mussweiler, 2003), the same is true with thinking in terms of social self-construal (i.e., "us") versus personal selfconstrual (i.e., "I"; Marx, Stapel, \& Muller, 2005; Stapel \& Koomen, 2001), and feeling we can versus cannot attain the standards set by a role model (Lockwood \& Kunda, 1997). Interestingly, all these variables are related to approach/avoidance experiences. Indeed, we often approach similar people (Newcomb, 1961), we approach more easily members from our groups (members of the "us"; Paladino \& Castelli, 2008), and finally, feeling that a role model is attainable can be equated with the feeling that we can approach his/her achievements. We believe this regularity is not a coincidence as approach/avoidance can be experiential information (Schwarz \& Clore, 2007) and other experiential information have been shown to moderate the impact of comparison information.

Hence, Häfner and Schubert (2010) suggested that what one experiences while processing comparison information (i.e., experiential information) moderates its impact on self-evaluation. Accordingly, they showed that experiencing easiness when processing comparison information (by being presented the fluent picture of an attractive or unattractive 
comparison target) favors assimilation, whereas experiencing difficulty in processing (by being presented a non-fluent picture) favors contrast effects. The problem with such a nice illustration is the recurrent problem with comparison information: they are often imposed by the context (Gilbert, Giesler, \& Morris, 1995) and one cannot choose the most self-protective information (e.g., a fluent picture of an attractive target or a non-fluent picture of an unattractive target). But if one cannot control features of the comparison information (e.g., its fluency), one can control more easily what she/he is doing while processing the targetnamely, moving toward or away from this information - , which would be another experiential information.

To understand why moving toward (approaching) versus away (avoiding) might be relevant experiential information in the social comparison context, it is fruitful to go back to the very definition of assimilation and contrast. Formally, assimilation happens when selfvalues move toward the standard (the comparison target's value), while contrast happens when self-values move away from the standard (Suls \& Wheeler, 2007). It might seem obvious that this definition refers to self-values, not the physical-self, but the embodied cognition literature suggests that the frontier between concepts (here self-values) and the physical world (here the physical-self) is not so clear-cut (Barsalou, 2008). Hence, feeling (i.e., experiencing) that the physical-self is moving toward or away from the comparison information might represent experiential information that translate into self-values. Somewhat in line with this contention, although in a different domain, Kawakami, Steele, Cifa, Phills, and Dovidio (2008) showed that information (math related concepts) processed while performing approach (vs. avoidance) arm movements were later associated with the self-concept—as measured with a me/not me Implicit Association Test (Greenwald \& Farnham, 2000). This suggests that approach/avoidance might be another experiential information. 
In sum, if, as we suggest, approach/avoidance is a relevant experiential information, processing comparison information while experiencing approach should induce a displacement of self-values toward the standard value whereas experiencing avoidance should induce a displacement of self-values away from the standard value. Consequently, approach could induce a higher self-evaluation with a high versus a low standard (assimilation), while the reverse should be true with avoidance (contrast). We therefore predict that approach versus avoidance will moderate the impact of comparison information on self-evaluation. We test this prediction using the same self-evaluation measures, but different approach/avoidance inductions in Study 1 and Study 2, and using the same induction, but different self-evaluation measures in Study 2 and 3.

\section{Study 1}

In this first study, we used a well-validated social comparison procedure adapted from Mussweiler (2001). Participants received information about a comparison target, either someone successful (a high standard) or someone unsuccessful (a low standard), and later performed self-evaluations on related dimensions. Importantly, before being presented comparison information, participants performed the approach/avoidance procedural priming procedure developed by Friedman and Förster (2005).

\section{Method}

\section{Participants}

One hundred forty-one participants (92 female, $\left.M_{\text {age }}=27.02, S D_{\text {age }}=5.03\right)$ were recruited to perform several (allegedly) unrelated online studies. All the participants were randomly assigned to the conditions of a 2 (approach vs. avoidance) by 2 (high vs. low standard) between-subjects design.

\section{Procedure}

Participants first completed a maze by performing arm-hand movements with their 
computer mouse. As shown in Figure 1, participants helped a cartoon mouse to find its way — from the middle to the exit of the maze — toward a piece of cheese lying at the maze's exit (approach) or away from an owl hanging over the maze (avoidance; Friedman \& Förster, 2005). In a second allegedly unrelated study on city adaptation (modeled after Mussweiler, 2001), participants then read about a same sex comparison target-Alex. Alex was described as adjusting either very well (high standard) or poorly (low standard) to her/his new city and professional activities. She/he developed lots of (high standard) or few (low standard) social activities and new friendships in the new city. Then, participants compared themselves with Alex and estimated, through an open-ended format, how often they went out with their colleagues per month and how many colleagues they hanged out with outside work. We later computed self-evaluated adjustment by z-transforming these two self-evaluative judgments and averaging them (Mussweiler, 2001) ${ }^{\mathrm{i}}$.

\section{Results and Discussion}

We conducted a 2 (approach vs. avoidance) by 2 (high vs. low standard) betweenparticipants ANOVA on self-evaluated adjustment. As can be seen in Figure 1, and as predicted, priming approach/avoidance moderated the impact of comparison on selfevaluation, $F(1,137)=6.00, p=.02, d=0.42$ (all other $p \mathrm{~s}>.12)$. Participants in the approach condition had their self-evaluation moved (although not significantly so, $t[137]=$ $0.65, p=.51, d=0.11$ ) toward the target value (assimilation). Conversely, participants in the avoidance condition had their self-evaluation moved away from the target value (contrast), which resulted in a lower self-evaluation when comparing with a high versus low standard, $t(137)=2.84, p=.005, d=0.48$.

This first study illustrates that experiencing approach/avoidance moderates the selfevaluative impact of comparison information. This supposes, however, that participants primed with approach/avoidance before processing comparison information would still have 
the corresponding experience while processing this information. Yet a more direct test of our approach/avoidance hypothesis would imply to have our participants literally moving forward (approaching) or backward (avoiding) while being presented comparison information.

\section{Study 2}

To test more directly our approach/avoidance hypothesis participants now performed approach versus avoidance movements while processing comparison information. As classical manipulations of approach/avoidance movements are sometimes ambiguous (Seibt, Neumann, Nussinson, \& Strack, 2008; van Dantzig, Zeelenberg, \& Pecher, 2009), we adapted Koch, Holland, Hengstler, and van Knippenberg's (2009) body locomotion procedure and had our participants moving themselves toward or away from comparison information. Unlike Koch et al. (2009) who had their participants walk a few steps (forward or backward) before a set of Stroop items, our induction allowed each comparison information to be displayed while participants were moving toward or away from comparison information. Consequently, our participants experienced approach and avoidance during the acquisition of information.

\section{Method}

\section{Participants}

Sixty-eight female students $\left(M_{\text {age }}=20.38, S D_{\text {age }}=3.58\right)$ received extra course credits to participate in what was presented as a cognitive psychology study dealing with the impact of locomotion on cognitive processes. All the participants were randomly assigned to the conditions of a 2 (approach vs. avoidance) by 2 (high vs. low standard) between-subjects design.

\section{Procedure}

Participants were standing in front of a 70x90 cm screen and first performed a bogus span task, which relied on the same procedure as the comparison task. We used this first task to fit with the cover-story and to have our participants practice the procedure necessary to 
receive each information while walking forward or backward. Within this procedure, participants had to walk two steps toward (approach) or away from (avoidance) the screen to receive each comparison information sentence (or list of numbers in the bogus span task). These sentences were displayed 700ms after participants left the central platform. By doing so, participants were on their way toward (or away from) the screen when sentences were displayed and experienced approach or avoidance movements while acquiring comparison information. Participants were instructed to go back to the central platform when the displayed sentence blanked out (sentence display durations varied depending on sentences length). Five comparison sentences described a second year student (Alex) and her/his adjustment to a new city and college. The remainder of the procedure was the same as Study 1, except that Alex's adjustment concerned a new city and new college instead of adjustment to a new job and new city. Accordingly, as a self-evaluated adjustment, participants now assessed how often they went out per month and how many friends they had in their college city (Mussweiler, 2001).

\section{Results and Discussion}

We conducted a 2 (approach vs. avoidance) by 2 (high vs. low standard) betweenparticipants ANOVA on self-evaluated adjustment. As can be seen in Figure 2, and as predicted, body locomotion moderated the impact of comparison on self-evaluation, $F(1,64)$ $=4.16, p=.04, d=0.50($ all other $p \mathrm{~s}>.21)$. Hence, participants approaching the screen had their self-evaluation moved toward the target value (assimilation), $t(64)=2.44, p=.01, d=$ 0.60. Conversely, participants moving away from the screen had their self-evaluation moved (although not significantly so, $t[64]=0.53, p=.59 d=0.13$ ) away from the target value (contrast).

Study 2 replicates Study 1 by showing that approach/avoidance moderates the selfevaluative impact of comparison information. In contrast with Study 1 where we manipulated 
approach/avoidance with a priming procedure before presenting comparison information, participants in Study 2 moved toward or away from the screen that displayed comparison information.

\section{Study 3}

After changing the approach/avoidance induction from Study 1 to Study 2, we now wanted to keep the same body locomotion induction, but extending our results by using totally different comparison information and self-evaluation measure. To do so, we adapted Häfner and Schubert (2010) by exposing our participants to pictures of moderately attractive or unattractive comparison targets and later asking them to evaluate their own attractiveness. With an exploratory purpose in mind, we also inserted a baseline condition in which participants were neither asked to move nor received comparison information.

\section{Method}

\section{Participants}

One hundred seventy-four students (109 female; $\left.M_{\text {age }}=21.48, S D_{\text {age }}=3.31\right)$ were paid $10 €$ for their participation. They were randomly assigned to one of the conditions of a 2 (approach vs. avoidance) by 2 (high vs. low standard) between-subjects design plus a baseline condition.

\section{Procedure}

The procedure was similar to Study 2 except that we changed the nature of comparison information and the self-evaluation measure. Instead of written comparison information, participants were now presented three pictures (of the same gender as the participants). They were asked to look at them carefully for a later recognition task. These comparison targets were either attractive (high standard) or unattractive (low standard) ${ }^{\text {ii }}$. Again, participants had to walk two steps toward or away from the screen to get each new comparison information (i.e., each picture). Then, amongst demographic questions, participants rated how beautiful 
and how intelligent they felt $(1=$ not at all to $10=$ very much $)$. We also measured selfevaluated intelligence to control for a general self-positivity bias.

\section{Results and Discussion}

We conducted a 2 (approach vs. avoidance) by 2 (high vs. low standard) betweenparticipants ANCOVA on self-evaluated attractiveness with self-evaluated intelligence as covariate $^{\mathrm{iii}}$. This analysis first revealed a positive relationship between self-evaluated attractiveness (i.e., attractiveness) and self-evaluated intelligence, $F(1,130)=86.49, p<.01$, $d=1.63^{\text {iv }}$. More critically, as can be seen in Figure 3, body locomotion moderated the impact of comparison on self-evaluation, $F(1,130)=4.53, p=.03, d=0.37$ (all other $p \mathrm{~s}<.53)$. Hence, participants approaching the screen had their self-evaluation moved toward the target value (assimilation), $t(130)=1.94, p=.05, d=0.34$. Conversely, participants moving away from the screen had their self-evaluation moved (although not significantly so, $t[130]=1.05$, $p=.29 d=0.18)$ away from the target value (contrast).

This study replicates the results of the first two studies while using the same induction as Study 2 for approach/avoidance, but with three major differences. First, we used pictures of three comparison targets, instead of sentences about one comparison target. Second, we used self-evaluated attractiveness, instead of self-adjustment to a city. Third, we used a direct measure of self-evaluation (from "I feel at all attractive" to "I feel very much attractive"), instead of a more indirect measure of self-evaluation (e.g., "I have 30 friends"). Despite these major differences, this study nicely replicates the other two, which enables to extend and to generalize our previous results.

\section{General Discussion}

As predicted, experiencing approach/avoidance while processing comparison information moderates its effect on self-evaluation. To the best of our knowledge, these are the first studies to show that approach/avoidance, both via priming (Study 1) and body 
locomotion (Studies 2 and 3), moderates the effect of comparison information on selfevaluation. Moreover, this was shown with both self-evaluated adjustment (Studies 1 and 2) and self-evaluated attractiveness (Study 3).

Although, the same (cross over) mean pattern was found consistently within our three studies, the two simple effects testing assimilation and contrast were not found significant within the same study. Therefore, to strengthen our conclusion, we conducted a meta-analysis using the "adding z-method" (see Rosenthal, 1978). This analysis confirmed that in approach conditions, self-evaluation moved significantly toward the target value (assimilation), $z=$ $2.87, p=.004$, while in avoidance conditions, self-evaluation moved significantly away from the target value (contrast), $z=2.52, p=.01^{\mathrm{v}}$.

These studies show that approach and avoidance lead to self-evaluative assimilation and contrast. This suggests that experiencing approach and avoidance are relevant experiential information giving the impression that one moves toward (leading to assimilation) or away from the target (leading to contrast). Hence, as it is true in other domains, it might be no coincidence that we use metaphors such as moving forward (Lakoff, 1987; Sherman \& Hoffman, 2007); those are sometimes based on truly physical experiences that influence the direction of comparison effect on self-evaluation.

Here we have proposed that approach/avoidance might be used as experiential information that the self is moving toward or away from the comparison target. It is still possible, however, that this link is more indirect. Indeed, the global/local processing style model suggests that approach induces a global/inclusive processing — which might favor assimilation — while avoidance induces a local/exclusive processing — which might favor contrast (Förster, Liberman, \& Kuschel, 2008). Future work could test for such mediation through global/local processing. 
Although, we showed that approach/avoidance moderates the self-evaluative impact of comparison information, some concerns remain. First, Mussweiler, Rüter, and Epstude (2004a, 2004b) have shown that contrast effects are more likely than assimilation when the standard is extremely high or low. Not having manipulated the extremity of the comparison standard, we do not know whether the moderation effect of approach/avoidance hold whatever the extremity of the standard. Second, we only relied on social comparison standards. Based on our theoretical reasoning, however, similar results should be found with other kinds or goals or standards (e.g., ideal self; Higgins, 1987).

These studies also raise a question related to the cognitive impact of comparison information. Indeed, comparing with superior others often threatens self-evaluation (Tesser, 1988), which distracts attention from the task at hand (Muller, Atzeni, \& Butera, 2004; Muller $\&$ Butera, 2007). The current work highlights that experiencing approach versus avoidance should respectively increase versus decrease the distracting effect of such comparison with superior others.

The literature taught us that, to feel better about ourselves, we often avoid information about Sherlock Holmes of all kinds, while favoring information about Homer Simpsons (Wills, 1991). The current studies suggest that to feel good about ourselves, we'd better (literally) run after the former, while running away from the latter. 


\section{References}

Förster, J., Liberman, N., \& Kuschel, S. (2008). The effect of global versus local processing styles on assimilation versus contrast in social judgment. Journal of Personality and Social Psychology, 94, 579-599.

Friedman, R. S., \& Förster, J. (2005). Effects of motivational cues on perceptual asymmetry: implications for creativity and analytical problem solving. Journal of Personality and Social Psychology, 88, 263-275.

Greenwald, A. G., \& Farnham, S. D. (2000). Using the Implicit Association Test to measure self esteem and self-concept. Journal of Personality and Social Psychology, 79, 10221038.

Häfner, M., \& Schubert, T. W. (2009). Feel the difference! The influence of ease experiences on the direction of social comparisons. Journal of Experimental Social Psychology, $45,291-294$.

Higgins, E. T. (1987). Self-discrepancy: A theory relating self and affect. Psychological Review, 94, 319-340.

Kawakami, K., Steele, J. R., Cifa, C., Phills, C. E., \& Dovidio, J. F. (2008). Approaching math increases math=me and math=pleasant. Journal of Experimental Social Psychology, 44, 818-825.

Koch, S., Holland, R. W., Hengstler, M., \& van Knippenberg, A. (2009). Body locomotion as regulatory process: Stepping backward enhances cognitive control. Psychological Science, 20, 549-550.

Lakoff, G. (1987). Women, fire, and dangerous things: What categories reveal about the mind. Chicago, IL US: University of Chicago Press.

Lockwood, P., \& Kunda, Z. (1997). Superstars and me: Predicting the impact of role models on the self. Journal of Personality and Social Psychology, 73, 91-103. 
Marx, D. M., Stapel, D. A., \& Muller, D. (2005). We can do it: The interplay of construal orientation and social comparisons under threat. Journal of Personality and Social Psychology, 88, 432-446.

Muller, D., Atzeni, T., \& Butera, F. (2004). Coaction and upward social comparison reduce illusory conjunction effect: Some support for distraction-conflict theory. Journal of Experimental Social Psychology, 40, 659-665.

Muller, D., \& Butera, F. (2007). The focusing effect of self-evaluation threat in coaction and social comparison. Journal of Personality and Social Psychology, 93, 194-211.

Mussweiler, T. (2001). 'Seek and ye shall find': antecedents of assimilation and contrast in social comparison. European Journal of Social Psychology, 31, 499-509.

Mussweiler, T. (2003). Comparison processes in social judgment: Mechanisms and consequences. Psychological Review, 110, 472-489.

Mussweiler, T., Rüter, K., \& Epstude, K. (2004a). The man who wasn't there: Subliminal social comparison standards influence self-evaluation. Journal of Experimental Social Psychology, 40, 689-696.

Mussweiler, T., Rüter, K., \& Epstude, K. (2004b). The ups and downs of social comparison: Mechanisms of assimilation and contrast. Journal of Personality and Social Psychology, 87, 832-844.

Newcomb, T. M. (1961). The acquaintance process. New York, NY US: Holt, Rinehart \& Winston.

Paladino, M.-P., \& Castelli, L. (2008). On the immediate consequences of intergroup categorization: Activation of approach and avoidance motor behavior toward ingroup and outgroup members. Personality and Social Psychology Bulletin, 34, 755-768.

Rosenthal, R. (1978). Combining results of independent studies. Psychological Bulletin, 85, 185-193. 
Schwarz, N., Clore, G. L., Kruglanski, A. W., \& Higgins, E. T. (2007). Feelings and phenomenal experiences Social psychology: Handbook of basic principles (2nd ed.). (pp. 385-407). New York, NY US: Guilford Press.

Seibt, B., Neumann, R., Nussinson, R., \& Strack, F. (2008). Movement direction or change in distance? Self- and object-related approach-avoidance motions. Journal of Experimental Social Psychology, 44, 713-720.

Sherman, S. J., \& Hoffmann, J. L. (2007). The psychology and law of voluntary manslaughter: What can psychology research teach us about the 'heat of passion' defense? Journal of Behavioral Decision Making, 20, 499-519.

Stapel, D. A., \& Koomen, W. (2001). I, we, and the effects of others on me: how selfconstrual level moderates social comparison effects. Journal of Personality and Social Psychology, 80, 766-781.

Stapel, D. A., \& Suls, J. (Eds.).(2007). Assimilation and contrast in social psychology. New York, NY, US: Psychology Press.

Suls, J., \& Wheeler, L. (2007). Psychological magnetism: A brief history of assimilation and contrast in psychology. In D.A. Stapel \& J. Suls (Eds), Assimilation and Contrast in social psychology (pp. 9-44). New York, NY, USA: Psychology Press.

Tesser, A. (1988). Toward a self-evaluation maintenance model of social behavior. In L. Berkowitz (Ed.), Advances in experimental social psychology (Vol. 21, pp. 181-227). San Diego, CA: Academic Press.

van Dantzig, S., Zeelenberg, R., \& Pecher, D. (2009). Unconstraining theories of embodied cognition. Journal of Experimental Social Psychology, 45, 345-351.

Wills, T. A. (1981). Downward comparison principles in social psychology. Psychological Bulletin, 90, 245-271. 
Footnotes 
Figure caption

Figure 1. The top panel presents the experimental setting (Study 1). The bottom panel presents the corresponding Mean self-evaluated adjustments (z-scores) as a function of approach and avoidance, and standard (high vs. low). Error bars indicate standard errors of the means.

Figure 2. The top panel presents the experimental setting (Study 2). The bottom panel presents the corresponding Mean self-evaluated adjustments (z-scores) as a function of approach and avoidance, and standard (high vs. low). Error bars indicate standard errors of the means.

Figure 3. Mean self-evaluated attractiveness (adjusted for self-evaluated intelligence) as a function of approach and avoidance, and standard (high vs. low). As these are adjusted means, no error bars are presented (Study 3). 
Running head: APPROACH AND AVOIDANCE IN SOCIAL COMPARISON

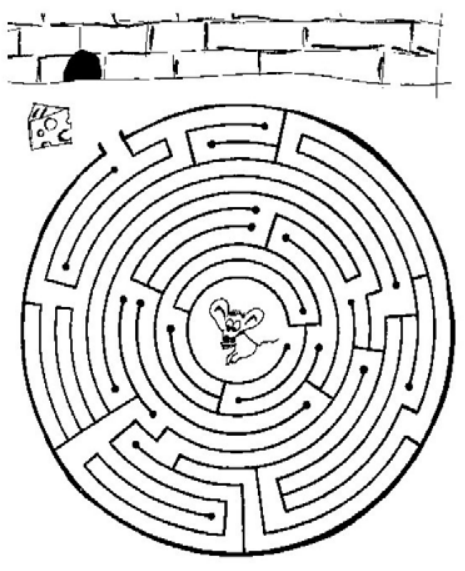

Approach

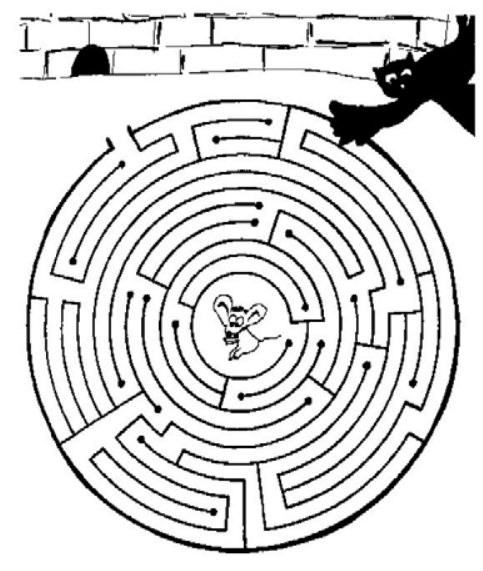

Avoidance

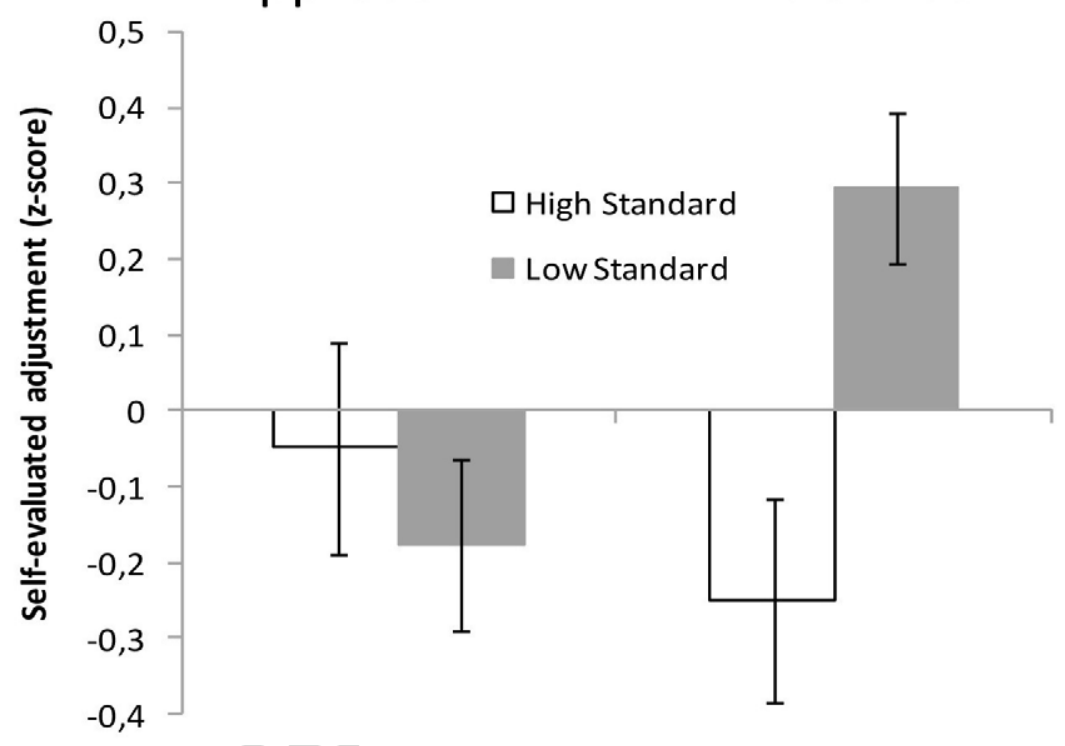

Fig. 1 

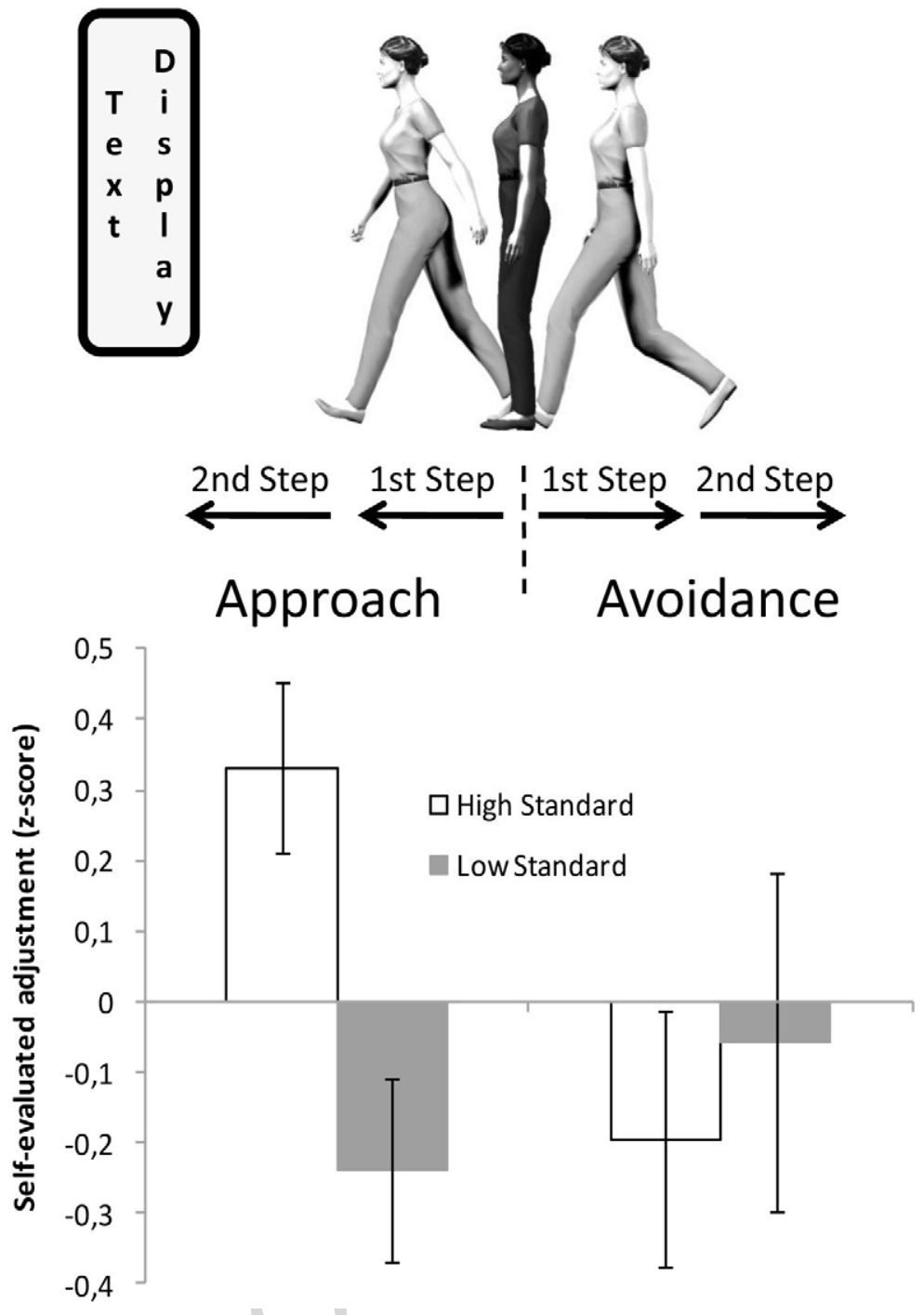

Fig. 2 
Running head: APPROACH AND AVOIDANCE IN SOCIAL COMPARISON

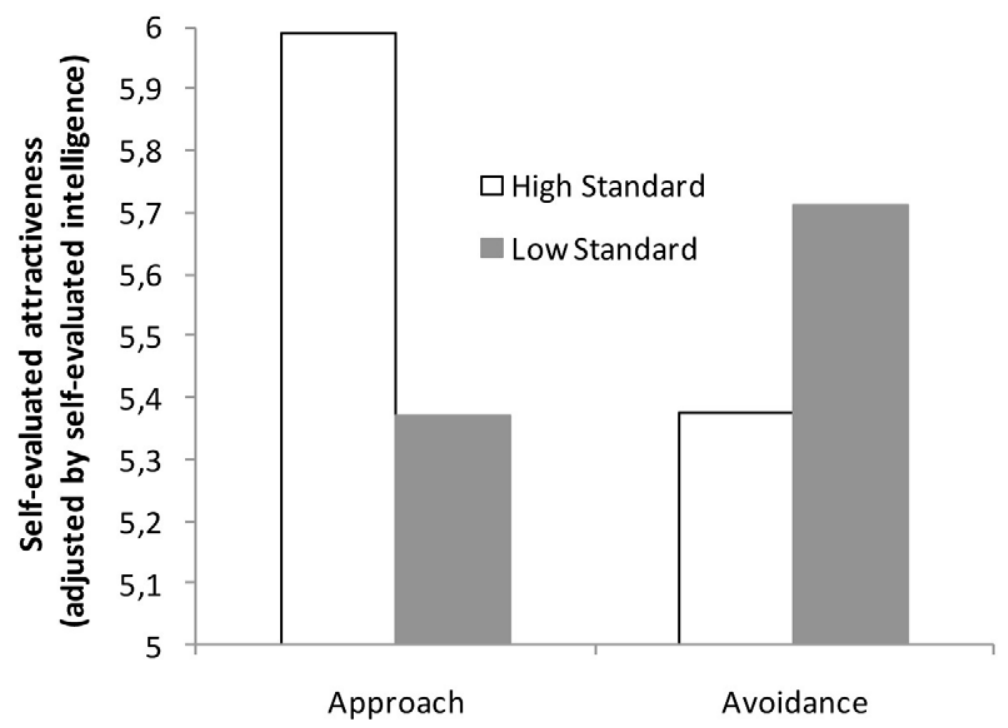

Fig. 3 
. In Study 1, responses were log-transformed to solve heteroscedasticity issues.

ii. A pretest revealed that attractive targets from both sex were rated more beautiful than the unattractive ones (all $F[1,37]>101$, all $p \mathrm{~s}<.01)$. Moreover, attractive and unattractive targets differed significantly from the middle of the scale (all $F[1,37]>5$, all $p \mathrm{~s}<.03$ ).

iii. The mean of the baseline condition $(M=5.71 ; S D=1.21)$ did not differ significantly from the four experimental conditions and fell close to the average of these conditions. It will not be discussed further.

${ }^{\text {iv }}$. Self-evaluated intelligence did not differ across conditions (all $p s>.21$ ).

v. Following Rosenthal's (1978), we also used two other methods ("adding logs" and "adding probabilities"), which led to the same conclusions (all $p \mathrm{~s}<.03$ ). Note that to be more conservative and in contrast with Rosenthal's suggestion, we conducted only two-tailed tests. 